\title{
Designing online help systems for reflective
} users

\author{
Milene Selbach Silveira \\ Faculdade de Informática, PUCRS \\ Av.Ipiranga, 6681, Prédio 30, Bloco 4 \\ 90619-900, Porto Alegre, RS, Brazil \\ milene@inf.pucrs.br
}

\author{
Simone Diniz Junqueira Barbosa, Clarisse Sieckenius de Souza \\ Departamento de Informática, PUC-Rio \\ R.Marquês de São Vicente, 225 \\ 22453-900, Rio de Janeiro, RJ, Brazil \\ simone@inf.puc-rio.br, clarisse@inf.puc-rio.br
}

\begin{abstract}
Empirical studies have revealed that most users are dissatisfied with current help systems. One of the causes for many of the problems found in help systems is a lack of coupling between the process for creating online help and the human-computer interaction design of the application. In this paper, we present a method for building online help based on design models according to a Semiotic Engineering approach. We argue that there may be important benefits to the users if designers communicate their design vision, and we also point at the need to change current design practices to encourage creative and intelligent use of computer applications. We show how this proposal opens a direct communication channel from designers to users, and we hope this will contribute to introducing this new culture.
\end{abstract}

Keywords: online help systems; Semiotic Engineering; HCI design; design models

\section{Introduction}

How can we help designers build online help for a computer application? And how can we ensure that it will adequately tell users what to do with the application, what the application is for, why certain design decisions were made, and so on? Typical online help systems don't help their users much. Although popular user interface design guidelines point to the need for carefully providing users with adequate help content $[18,31]$, users are still dissatisfied or have trouble with current help systems $[6,26]$. The reasons for this inefficiency may lie in inadequate design processes, in lack of time or planning, in excessive confidence on the intuitiveness of a failproof interface, or even in a naïve acceptance of current standards [26].

Most help systems focus on operational information based on task models. They present users with "how to" information, implicitly accepting the "paradox of the active user" [5], and embrace the vision that online help is to be used only as a last resource when users don't know what else to do. The result is what is known as "fail-proof" interfaces, in which users' actions are con- strained in order to avoid mistakes, and in which users are never informed about "why" (or "why not") the application behaves in a certain way.

Opposite to the desire to create fail-proof user interfaces, we find Adler \& Winograd's views that attempting to build idiot-proof technology underestimates or hinders the users' intelligence and creativity to learn and transform software according to their needs [1]. In accordance with their view, we believe that the role of the online help system is to open new possibilities and give users resources to understand and go beyond the designer's original ideas, taking most advantage of the technology. Users would be motivated to move from an "active" attitude to a more "curious and creative" one. In this view, the construction of the online help system becomes a critical step in the design of human-computer interaction (HCI). We want to give users access to minimalist and strategic information to encourage creative and intelligent use of computer artifacts.

This work is based on Semiotic Engineering [9], which views the user interface as a message sent from designers to users, representing the designers' solution to what they believe is the users' problems. It is through this 
message that designers tell users what they have interpreted as being the users' needs and preferences, what the answer for these needs is and how they implemented their vision as an interactive system. In Semiotic Engineering, online help is an essential application component. This is where designers will explicitly "speak" to the users, revealing how the application was built, how it can be used and for what purposes.

This paper describes a model-based method for online help system design, stemming from Semiotic Engineering and driven by two main pillars: communicability [21] and the rhetorical layering technique used in the minimalist approach [11]. In order to illustrate our approach, the design of a real application's help system is presented as a running example.

\section{A Semiotic Engineering View of Online Help}

According to the Semiotic Engineering theory, help systems are a distinguished meta-message from designers to users [9]. In this case, the designer is explicitly saying what he believes are the users' problems or tasks, what he thinks is the best solution for them, and how he intends to make it available for practical use. To this theory, it is essential that users understand the designers' message so that they may better use and take advantage of the application.

The help system is a privileged communication resource. Typically, help design focuses on designer-touser communication of extensive help content, including keyword searches as the only means for users to express their doubts. In our approach, we provide users with an additional communicative resource: the ability to express specific doubts situated in the immediate interaction context. The idea is to promote a novel perspective on online help design and usage: Users should be able to express more precisely their doubts and needs, and designers should be able to anticipate such doubts and needs, and to organize their response accordingly.

The major problems users report with respect to existing help systems are [14]:

- help systems don't provide the specific information desired;

- help information is not available when needed;

- help information is not accurate or is incomplete; and

- it is difficult to switch between the help system and the application.
When asking for help within an application, users have specific doubts that they need to clarify. The frequent users' doubts are summarized in Table $2[3,30]$.

\begin{tabular}{|c|c|}
\hline Types of Questions & Sample Questions \\
\hline Informative & $\begin{array}{l}\text { What kinds of things can I do with this } \\
\text { program? }\end{array}$ \\
\hline Descriptive & What is this? What does this do? \\
\hline Procedural & How do I do this? \\
\hline Interpretive & $\begin{array}{l}\text { What is happening now? Why did it } \\
\text { happen? What does this mean? }\end{array}$ \\
\hline Navigational & $\begin{array}{l}\text { Where am I? Where have I come from? } \\
\text { Where can I go to? }\end{array}$ \\
\hline Choice & What can I do now? \\
\hline Guidance & What should I do now? \\
\hline History & What have I done? \\
\hline Motivational & $\begin{array}{l}\text { Why should I use this program? How } \\
\text { will I benefit from using it? }\end{array}$ \\
\hline Investigative & $\begin{array}{l}\text { What else should I know? Did I miss } \\
\text { anything? }\end{array}$ \\
\hline
\end{tabular}

Table 1: Taxonomy of Users' Frequent Doubts.

A large body of research has been developed in an attempt to effectively help users overcome these problems and attain their goals, i.e., acquire the desired information $[7,8,12,13,15,16,17,23,27,28,33]$. Our research draws on communicability evaluation [21] and the layering technique used in minimalist documentation [11] to build on existing research and propose a novel approach to online help design.

\subsection{Comunicability evaluation}

In the communicability evaluation method [21], utterances are used to characterize users' reactions when a communicative breakdown occurs during interaction. It is argued that these breakdowns occur when the user cannot perceive the designers' intended affordances. A communicative breakdown is an indication that the designers have failed in conveying their message through the application interface.

The utterances used in communicability evaluation are:

- Where is?

- What now?

- What's this?

- Oops!

- I can't do it this way. 
- Where am I?

- What happened?

- Why doesn't it?

- Looks fine to me.

- I can't do it.

- I can do otherwise.

- Thanks, but no, thanks.

- Help!

By observing users' behavior during interaction, evaluators assign communicability utterances to the breakdown situations they identify from interaction "symptoms". The communicability utterances were elaborated as an attempt to evoke the users' apparent doubts during interaction, precisely at the moment of breakdown. Our work aims to provide users with access to similar expressions to represent their actual doubts during interaction. In the approach described in this paper, users can express themselves using a set of predefined utterances whenever they experience a communicative breakdown during interaction.

It may be argued that many applications already provide access to specific help information by means of expressions such as What's this?. This is typically afforded by specific interface elements, such as pop-up menus, for instance. The ideas presented here extend this approach to all levels of help content, providing relevant, context-sensitive information at varying granularity.

\subsection{Levels of affordances}

In order to further help designers to organize help content, we also examine in detail the role of affordances in Semiotic Engineering. In de Souza, Prates \& Carey [10], we see that the designer has fostered a successful communication with users when they can perceive the intended application affordances. The authors classify affordances in three levels: operational, tactical, and strategic.

Affordances at the operational level are related to the immediate and individual actions that users need to perform. They are closely related to the interactive codes employed in the application, i.e., the concrete user interface. We may consider questions such as What's this? as being answered at this level.

Tactic-level affordances are related to a plan, or sequence of actions, for executing a certain task. In general terms, information at this level answers questions such as How?

Finally, there are strategic-level affordances, which are related to conceptualizations and decisions involved in certain problem-solving processes and in the embedded technology. Information at this level typically answers questions of the kind of Why?

\subsection{Using communicability utterances in help design}

In this section, we will analyze the relation between each communicability utterance, the corresponding communicative breakdown as indicated by certain symptoms [21], the affordance level in which it occurs, and the kinds of help response to be designed. Our goal is to gain insights for designing coherent help systems that provide content at various levels, and for designing consistent access for each piece of content.

\section{Oops!}

Oops! occurs when the user realizes he/she has just done something wrong, and wants to reverse the previous action(s). The help response should be either operational or tactical, depending on the complexity of the steps to be performed. For instance, a single Undo would be considered an operational response, whereas a sequence of interaction steps that lead to the desired state would be tactical.

\section{Where is?}

The problem here is that the user has an idea of what he/she needs, but cannot find the corresponding interface element. The help response should be, at first, operational: it should tell the user where the element is. It may be necessary to actually show where the element is, depending on the interaction steps required for accessing it. In this case, the response is considered tactical, showing how the user may reach the element.

It is important to note that, in the case of this utterance, the user must specifically describe or identify the element he/she is querying about, since its location is unknown. It is possible that the user does not know the specific name or expression the designer chose to refer to the element, so we should be aware of this problem and provide a variety of synonyms for the terms employed throughout the application.

Where is? utterances can also occur from within help content that was first accessed via other utterances. In this case, the user was told what to do, but does not know where to find the necessary interface element for carrying out the instructions. For instance, let us consider some help content related to an Oops! utterance, which tells the user what to do to reverse the previous actions. If there is 
an element the user cannot find in the interface, he/she would further utter Where is? in order to find out the location of (operational) and/or interaction steps required for accessing (tactical) the element.

\section{What now?}

This utterance occurs in two different situations:

(i) when the user has carried out a few interaction steps but does not know how to proceed with the task at hand; or

(ii) when the user needs to perform a task that he/she cannot even formulate in terms of the available interface elements.

In the first case (i), the response should be operational, showing the user what to do (what the next step is). If the user utters What now? again, in this context, the response should become tactical, showing the user how to do what is needed.

In the second case (ii), the response would be strategic, presenting to the user the tasks the application was designed to support, from a user's perspective, i.e., using the terms he/she should be familiarized with, according to the corresponding domain.

\section{What's this?}

The user utters What's this? when he/she needs a description of an interface element or its usage. The response should be, at first, operational, describing the element. If the user wants further information, such as how, where, and when the element is used, we have another What's this?, this time at a tactical level, describing the element's usage. In many cases, both levels can be presented at once, saving users' an additional interaction step.

Another usage of What's this? may occur when the user has heard about some application object or functionality, but could not identify or locate it. In this case, the access to the utterance would be like the one for Where $i s$ ?, in which the user is prompted for additional input.

\section{What happened?}

This utterance occurs when the user performs an action expecting a response, and he/she gets another response, or no response at all. The corresponding help content should be both operational and tactical: It should reveal what happened, and how it resulted from the previous interaction steps.

\section{Why doesn't it?}

Why doesn't it? occurs when a user retries an operation more than once, because he/she is convinced that he/she is doing the right thing. The response should be both tactical and strategic. It should show the consequences of the interaction steps taken, and why they provide those results.

\section{I can't do it.}

I can't do it. could be accessed from a piece of help content, whenever the user fails in following procedural instructions. The response should be presented at a tactical level, guiding the user through the preconditions necessary for that task to be performed. It may also present operational instructions, at a finer level of interaction detail.

\section{Help!}

This utterance gives access to a traditional facet of the help system, when uttered within the application interface. Moreover, it can also be uttered within the help system itself, and in this case, it should provide information about all kinds of help that are available to users. In this context, it can be used again to ask when and how to access the various portions of the help system.

\section{Unused communicability utterances}

Some of the existing communicability utterances are inadequate for accessing help information. For instance, the user would never utter I can't do it., but rather ask How do I do this?. The utterances I can do otherwise (missing of affordance) and Thanks, but no, thanks. (declination of affordance) wouldn't probably be uttered either, because the user would have successfully completed his/her task.

\section{Additional help utterances}

In addition to the communicability utterances selected for accessing help content, we need new utterances to convey the users' frequent doubts that are not addressed by communicability, like procedural and motivational doubts.

Due to the fact that user interfaces have become increasingly more flexible, we also need some information to convey more than one way to achieve a single goal, e.g. how different user interface elements may be used to achieve a goal. We do so by providing a response to the question Is there another way to do this?.

In order to address a procedural doubt, a new utterance is proposed: How do I do this? In addition, we pro- 
pose a few other utterances: Where was I? Why should I do this? What is this for? Who is affected by this? On whom does this depend? Who can do this? Following is a description of the breakdowns they intend to solve, and the levels at which they function.

\section{Where was I?}

This breakdown occurs when the user needs to retrace his/her previous steps in order to understand the state in which he/she currently is. The response should be at both the operational level, with an identification and a description of the previous steps, and at the tactical level, with an identification of larger tasks that may comprise these steps.

\section{Why should I do this? What is this for?}

These utterances could be accessed from a piece of help content, whenever the user doesn't understand the reasons underlying certain instructions or the utility of a certain task. The response - for both of them - should be presented at a strategic level, revealing the designer's perspective on that topic.

These utterances are particularly important to Semiotic Engineering, because the designer can use them to explicitly state his/her rationale of the application.

For instance, Why should I do this? could be used from within a piece of help content previously accessed via a tactical What's this?. In this situation, the user would want to know not only what a task is and how to perform it, but also its importance within the application as a whole.

\section{Who is affected by this? On whom does this depend? Who can do this?}

These utterances may occur when work processes and roles are modeled, and roles are responsible for interdependent tasks. The response may be considered operational, listing the roles affected by the selected task.

\section{How do I do this?}

When the user does not know how to perform a certain task in an application, he/she may utter How do I do this? and provide additional input in order to obtain the corresponding help information. The response should be presented at a tactical level, describing how he/she should proceed. Typically, it consists of step-by-step instructions.

Within this help context, users may utter How do I do this? again, in case an instruction isn't clear. If, on the other hand, he/she tries to perform the operation and doesn't succeed, it is a case of I can't do it.

\section{Is there another way to do this?}

This utterance comprises both I can do otherwise and Thanks, but no, thanks. In this case, the response is both tactical and strategic. For each alternative path of interaction, it should present the steps required to perform the task (tactical), and the motivation for following that path (strategic).

This utterance is also characteristic of our Semiotic Engineering approach, since it allows the designer to explicitly convey his/her design decisions and intentions.

As presented earlier, some utterances can be accessed immediately from the user interface, such as What's this? and What happened?. Others, however, require additional input, such as Where is? and How do I do this?. Moreover, some utterances may occur from within the help system itself, such as Why should I do this?, for example.

Table 2 presents the whole set of utterances we will use for designing our help system.

\begin{tabular}{l} 
Existing Communicability Utterances \\
\hline I can't do it. \\
Oops! \\
Where is? \\
What now? \\
What's this? \\
What happened? \\
Why doesn't it? \\
Help! \\
\hline Help-Specific Utterances \\
\hline How do I do this? \\
What is this for? \\
Why should I do this? \\
Whom does this affect? \\
On whom does this depend? \\
Who can do this? \\
Where was I?
\end{tabular}

Table 2: Final set of utterances for accessing help content.

Both users and designers benefit from using these expressions: users have a greater chance of getting a rele- 
vant help response, and designers have an organizing principle directly driven by the communicative breakdowns they intend to circumvent or solve.

\subsection{Minimalism and the layering technique}

Because the proposed help expressions allow users to focus on a specific doubt, designers need now to elaborate help content to address each one of these doubts. This allows for shorter, more focused help responses. This idea is in line with the minimalist approach to instructional material [4].

Inspired by the layering technique [11], we allow users to access minimal pieces of help content about a certain user interface element or task. From this help content, users may, depending on their needs, access further help material and then on to as much further information as required.

A simple example illustrating minimalist responses and the recurring use of expressions upon these is shown in Figure 1. This is a fictitious example, based on some help content found in Microsoft Word $\AA$, as a response to help requests about 'tracking changes'.

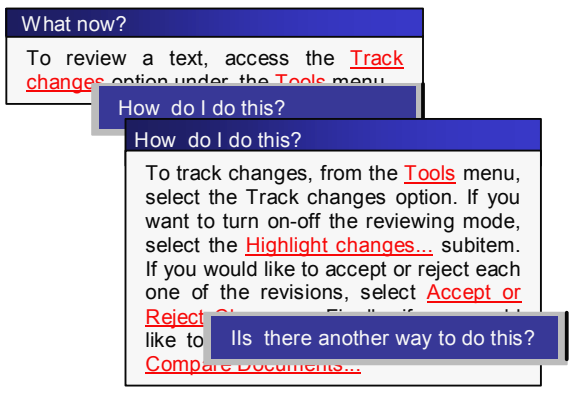

Figure 1: Help responses and their recurrence.

Combining the layering technique and the communicability utterances for accessing help content allows designers to solve many context-sensitive doubts, i.e., doubts regarding their immediate and contextual needs. However, this approach is somewhat limited when users have major gaps in understanding the application. In this case, we need a more traditional standalone help module.

In the standalone help module, it is possible to find related information about the domain and the application as a whole, as well as usage scenarios. It is through the standalone help module that designers may convey their global design vision in a consistent way, and address general understanding issues, such as the application domain, advantages and disadvantages of using the aplication, and provide content from a tutorial perspective. Because most research on help systems addresses some of the major design issues of standalone help modules, in this paper we will focus only on the local (contextualized) help.

\section{Building online help systems from HCI design models}

In our approach for designing online help [32], we propose that the designer's vision - to be sent to users through the help system - be captured during the design and development processes. This knowledge elicitation (capturing the designers' knowledge about the application designed and developed by themselves) is based on questions for the designers, classified into three major topics. From the designers' point-of-view:

- What are the users' problems/needs?

- What is the best solution for these problems? And what are the alternatives?

- How was this made available for operational use?

These questions summarize our conclusions after relating the aforementioned users' most frequent doubts, research about available technical literature (taxonomies for online help systems [29], context-sensitive help [16, 33], help for the web [7, 23, 28], and user-system dialogues $[8,12,13,15,17,27])$ and practice in the design and development of online help systems for groupware applications on the web.

Each topic can be extended into subtopics, whose answers constitute the semantic dimension of the message from designers to users about the application. These are:

\section{What are the users' problems and needs?}

- What is the application domain?

- What is the nature of work in this domain?

- Who are the actors?

- What role do they carry out?

- What tasks do they do?

\section{What are the best solutions for these problems and} needs?

- What is the application?

- How will this technology affect the domain?

- What is possible to do with it (What are the supported users' goals)?

- What is the application useful for?

- What are the advantages of the application? 


\section{Regarding the technology}

- What computational environment is presumed for the full operation of the application?

- What does the user need to know in order to use this application?

\section{Regarding the supported activities}

- What activities (tasks) can be carried out in the application environment?

- What are the available options in the current version?

\section{How can all of this be put to operational use?}

\section{Regarding the HCI Analogy}

- What is the basic computer-human interaction analogy used?

\section{Regarding the tasks}

- What does each task mean?

- How can/must users do that? When?

- Where in the application can users do this task?

- How can users do and undo (parts of) tasks?

- Why is it necessary to do this or that task?
- Examples of performing the task (scenarios)

- Who is or isn't affected by a task or part of a task?

- What do we do after finishing a task? Until when can we do that?

- How do we know if we have (successfully) finished the task?

\section{Given an actual context of interaction, the user must} be able to answer:

- What can I do now?

- Where am I?

- Where can I go?

- Where did I come from?

- What happened?

We can analyze these questions from four different perspectives: Domain, Tasks, Agent (inspired by [34]) and Application. These perspectives are used to define our help model (Figure 2). The expressions in boldface represent the corresponding help information. In parentheses, we present the questions for the designers, whose answers will be used to build the actual content of the help topics.

domain (What is the application domain?)

description (What is the nature of work in this domain?)

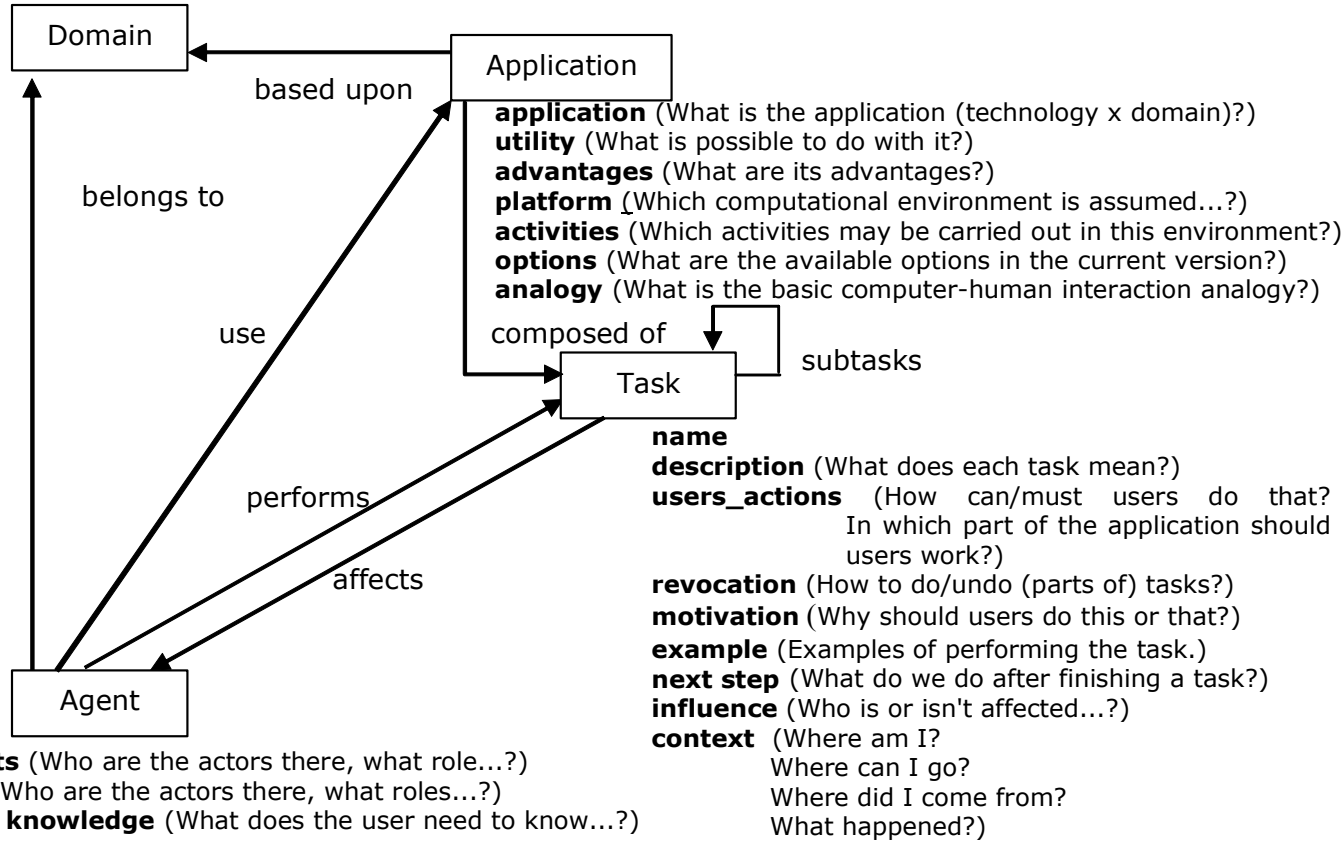

role (Who are the actors there, what roles...?)
basic knowledge (What does the user need to know...??)

What happened?)

Figure 2: Perspectives for representing information in help systems. 
In this model, we find the answers to the described questions. The entities' attributes become the answers to the preceding questions, which are listed under each corresponding entity. The questions of a contextual nature are generated at execution time, according to the task and the actual application state.

After comparing the proposed help model with existing HCI design models, we realized that some of the information necessary for developing help systems is already present in well-known design models. As such, instead of building a distinct model specifically for help design, we propose to use the HCI design models as a starting point, and extend them with additional information that we deem valuable for help design.

In HCI design processes, many designers use models to represent interactive solutions in such a way as to support their reflection and decision-making process. Perhaps the most widely used models are the task models, but we also find references to user, domain, presentation, and dialogue models, among others [20, 22, 24, 25].

Puerta [24] remarks that from the design models we may derive answers to several questions, which would guide the design team throughout the development process. Among these questions, we cite:

- Who are the users of the user interface?

- Which tasks do users perform using the interface?

- To which domain objects does the interface need to give access?

- How the user interface components are presented to each user?
- Which commands and actions can the user execute in the interface?

Although this information is essential for the application design, we claim that they are not enough for designing the online help system. In addition to these functional issues, we need to provide information about the designer's vision of the application, as described earlier in this section. In particular, we need resources to answer:

- What is the nature of work in the application domain?

- How will this technology affect the domain?

- Why is it necessary to do this task or perform that action? Whom will it affect? On whom does it depend?

- Why this or that interaction path is preferred?

Because we want to reuse available design information, we have studied existing design models to assess what kinds of information were represented, and which ones we would have to add to the models. First, we refined the help module presented in Figure 2. To better represent tasks in the necessary level of detail, we included the components Actions and Interface Elements. The set of design models we chose is composed of domain, application, task, user, interaction and interface models (Figure 3). Note that there is no specific help model. Instead, we extended each design model to be able to represent specific help information that was missing. 


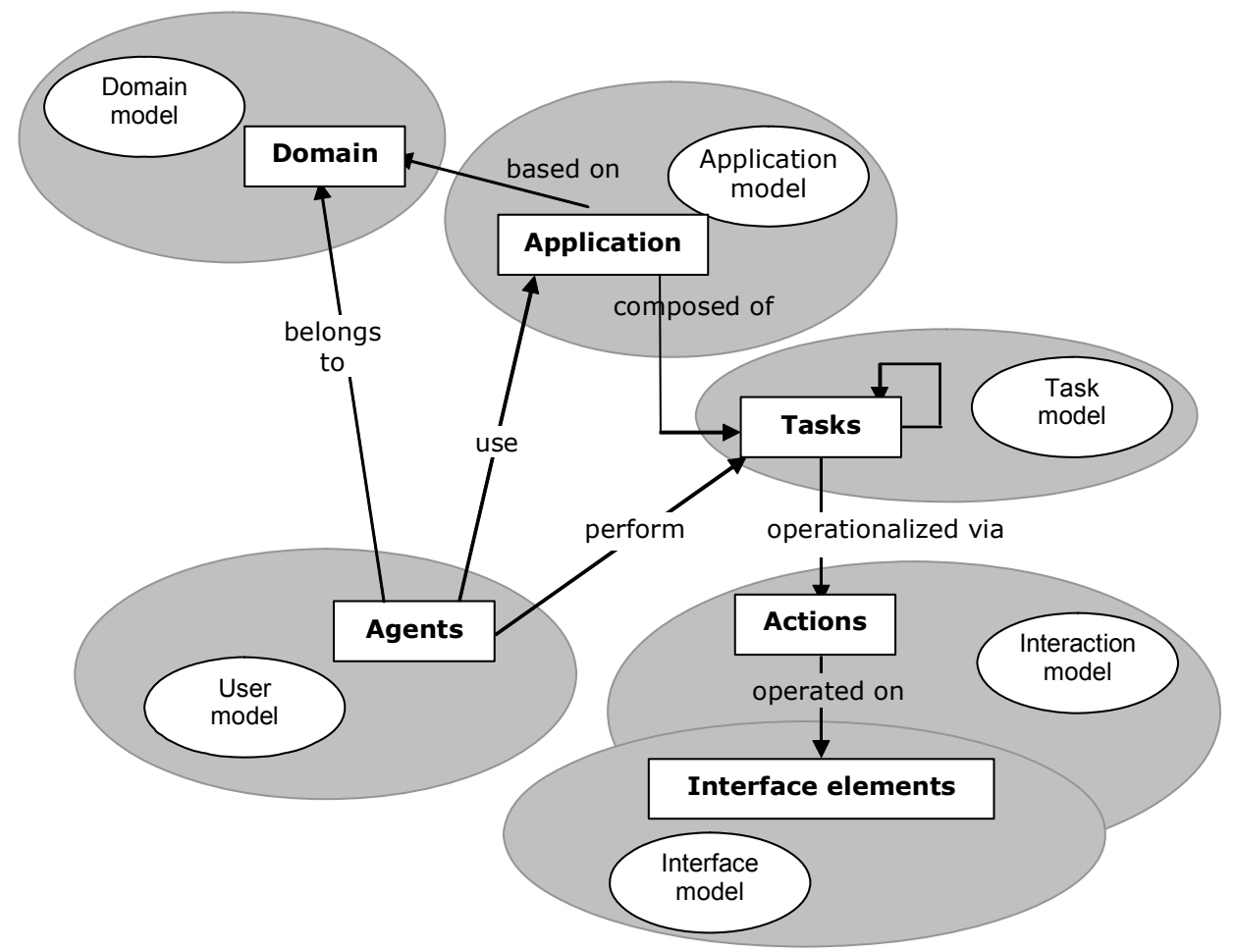

Figure 3: Help model and the corresponding design models.

Most of these models - domain, task, and user models, as well as part of the interaction model- are independent of the specific technology in which the system will be developed. The user interface model and the part of the interaction model that represent the operationalization of the tasks, however, will depend on both the user interface style and implementation platform.

Designers build these models during diverse phases of the HCI design process. Figure 4 illustrates a generic schema of the design lifecycle, and in which phase(s) each model is built.

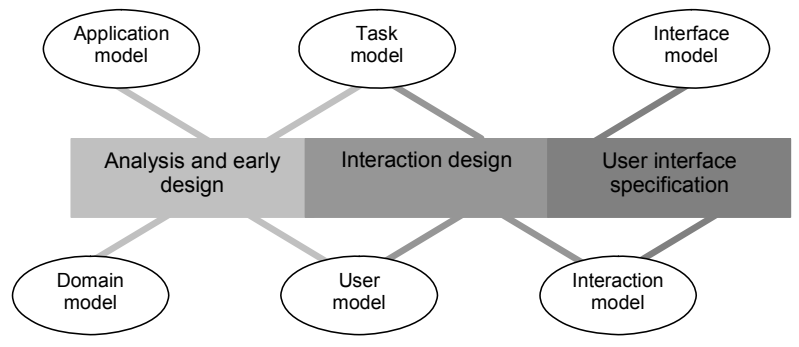

Figure 4: Design models used during the each phase of the design process.

The distinction between the domain, application, user and task models is clear cut. But the distinction between the interaction and the interface model needs further clarification. It is possible to model tasks by means of their realization in the user interface ("to do $\mathrm{X}$, click on the Y button"). But what if the technology or the user interface style changes? Although many important decisions regarding interaction were made, designers will have to elaborate everything again to address the new technological environment. This work assumes that the technology-separable aspects of the interaction will be represented in the interaction model [2], whereas the concrete realization of the user interface is left to the interface model.

An interesting question may be raised from the diagram in Figure 4: Does the moment at which each model is built affect the online help system design? One might think not, as long as the information is available when necessary. However, good HCI design somewhat presupposes such an order, otherwise misconceptions may arise. For instance, is it possible to capture domain information only when the task model is being built? In principle, yes, but a global knowledge of the domain is essential before starting to model tasks - even if this knowledge needs to be refined later. Otherwise, how would designers elaborate the technology to support tasks before understanding how the tasks are currently performed in the users' work environment? How would they identify the need for new tasks? And how would they be able to assess how the technology will impact the daily work of users, in order 
to minimize undesirable effects?

In projects that do not follow a sound model-based development process, help designers must face additional problems: The information necessary for building help is not captured when it is first available, and the help system is built only at the end of the process. That way, not only do help designers lack time to elaborate the help content, but also they are not told the rationale underlying design decisions that may affect how they should tell users how to use the system.

We now describe the information comprised in each model, highlighting (in boldface) the information that is essentially driven towards help system construction.

\section{Domain model}

This model contains information related to the application domain, focused on its description, the nature of work performed, and the information elements (domain signs ${ }^{1}$ ) that belong to it.

\section{Application model}

This model represents the application being designed. The focus here lies in the application description, its utility, advantages, supported activities, alternative courses of action, and the application signs. Besides, it encompasses the roles users may play in this application, and for each role, the tasks related to it, and the necessary basic knowledge.

\section{Task model}

This model comprises information related to the tasks users may perform. For each possible task, we represent its description, utility, reason why it should be performed (from the designer's point of view), its parent task (considering a hierarchical task decomposition), the operator $^{2}$ that connects it to the following task, which establishes in which way it should be executed, the task's preconditions, and the related domain and application signs.

\section{User model}

In this model, we represent information related to the targeted application users. For each user we represent his name, the roles he may play, and his profile, which indi- cates the way in which he would like to interact with the application.

\section{Interaction model}

This model represents the possible forms of interaction with the application, that is, how to effectively perform a certain task in the application. For the execution of each task there may be alternative courses of actions. For each alternative, there is the reason why it should be executed (from the designer's point of view), its precondition(s), the indication whether it is the preferred alternative (from the designer's point of view) and the actions necessary for its execution. For each action, there is the default value, as well as the way to undo it, besides the operator that connects it to the next action.

\section{Interface model}

This model is composed of information about the interface elements of the application. For each element, we represent its type, the values it may assume, its default value, its location at the user interface, and the related domain and application signs.

\section{A method for developing online help}

In this section we describe the steps in designing an online help system in a model-based design:

(i) HCI design model construction, taking into account specific help issues;

(ii) automatic generation of draft help content;

(iii) content refinement and recurrence specification;

(iv) standalone help module construction;

(v) connection of help access points to the interface elements;

(vi) preliminary testing and usage analysis during communicability evaluation; and

(vii)help content refinement or redesign.

This method is illustrated in Figure 5.

\footnotetext{
'A sign is a technical semiotic term that is usually taken to mean "something that stands for something else for someone". In this sense, every piece of data represented in a computer application is a sign to the designer, and every user interface element is a sign both to the designer and to the user(s).

${ }^{2}$ The operators considered in this version are those proposed in [20].
} 


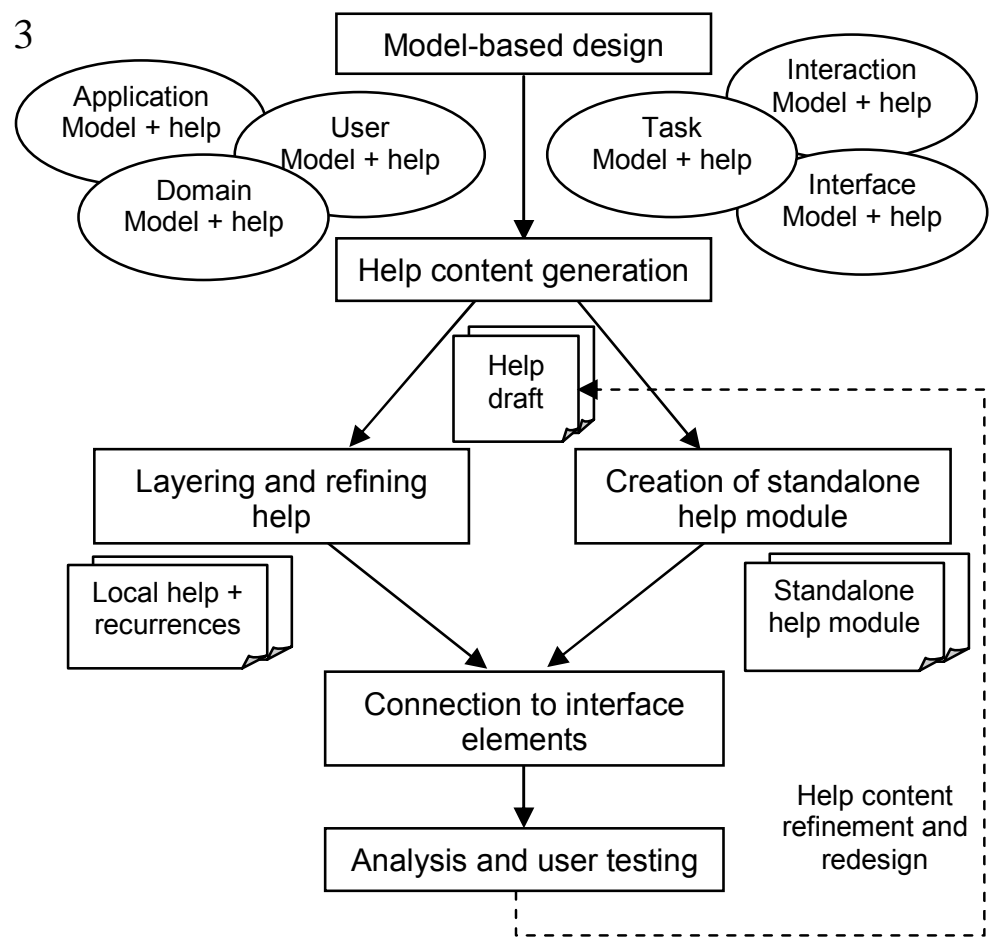

Figure 5: Steps used to build online help systems.

To illustrate our approach, we will describe portions of an application we designed and developed for supporting the volunteer work in a nongovernmental organization [19]. The module we have chosen for illustration is the Bulletin Board, in which volunteers and employees of this organization may post and verify announcements related to their work or to the organization as a whole. These announcements may be classified according to different topics or divisions within the organization, such as: Administration, Events, Meetings, and so on.

Figure 6 illustrates a usage scenario in the actual application, in which a member of the organization has looked for help about a section marker.

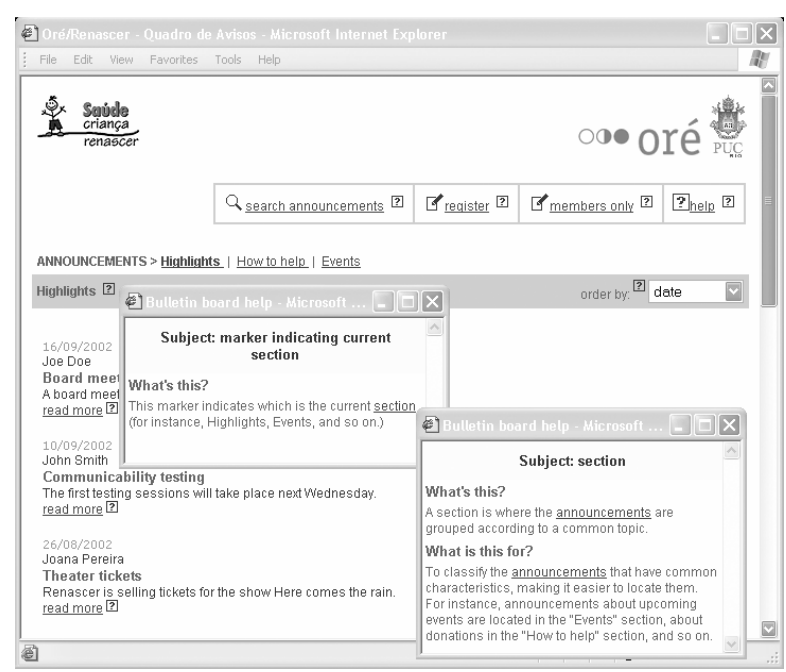

Figure 6: Help request and response.

\subsection{Representing help content in HCI design models}

As mentioned before, we derive the information necessary for the construction of both local help responses and the standalone help module from HCI models built during the design process. 
In order to create an announcement you should provide the required information and confirm the operation.

\subsection{Layering and refining help and creation of standalone help module}

Based on the interviews with users, domain analysis, and so on, the designer selects those elements about which she believes users may have doubts or which she would especially like to explain or describe to users, and the expressions that will be used to access the corresponding help content.

As soon as these element-expression pairs are selected, the generated draft responses undergo a refinement process, in which technical communication specialists shape the text to better communicate the designer's message to users. Having done that, each help response is analyzed by the designer to verify the possible recurrence points it may comprise. These points indicate the elements in the response to which further help expressions and content may be associated. This content may, in turn, contain additional recurrence points, and so on, deepening the help content about certain interrelated topics.

In our example, the draft text of the selected responses was refined and analyzed with the purpose of finding possible recurrence points. For instance, in the response to the expression What's this?:

This marker indicates which is
the current section (for in-
stance, Highlights, Events, and
so on.)

the designer verified a reference to another domain sign, in this case section. She selected this word as a recurrence point within the response, and associated the expressions What's this? and What is this for? to it.

The template for What's this? of a domain sign is: description (<sign $>)$; and the template for the expression What is this for? is: purpose $(<\mathrm{sign}>)$. Thus, the response to What's this? is:

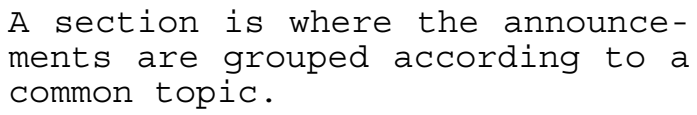

And the response to What is this for?:

To classify the announcements
that have common characteris-
tics, making it easier to locate
them. For instance, announce-
ments about upcoming events are
located in the "Events" section,
about donations in the "How to

help" section, and so on.

It is important to note that, whenever possible, help responses are generated and refined beforehand and embedded in the application as static information, instead of being dynamically generated. This solution avoids execution delays in processing the possible expressions and responses for each element, and makes it possible to manually refine the generated draft responses, so that the manner of speech will seem natural and the communication will be more efficient.

Jointly with the layering and refinement of the help messages, the standalone help module may be created. In its most basic form, this module should contain help information about the domain and the application, as well as an explanation about how different kinds of help work (standalone and local). The domain and application portions of this module may be built and refined pari passu the construction and refinement of local help content. Afterwards, part of the local help content may also be included in the standalone module.

\subsection{Connection to interface elements}

Having refined the local help content, the expressions and their corresponding responses may be made available through the user interface, associated to the elements which, according to the help designer, may raise some kind of user doubt. This is achieved by adding a trigger or link to the corresponding help expressions and content. In our case study, the graphics designer created a symbol to function as a link to local help requests. The chosen symbol was an interrogation mark within a square, such as ?, placed next to the user interface element associated to the help expression.

\subsection{Analysis and user testing}

Having built the application prototype, the local help system and the standalone help module, the design team should carry out some preliminary testing in order to verify whether the expressions and the corresponding responses are consistent, as well as the general help information. Every connection to help should be tested, as well as every recurrent point within the responses.

Once the application is implemented, it is ready for real user testing. We use the communicability evaluation method [21] to verify if the interface is conveying the designer's message and to investigate which problems might occur during interaction. In our case study, we set up a few sessions of communicability evaluation with six users with varying degrees of computer literacy. These users were selected specifically because they represented the majority of the targeted user population, as indicated 
by the analysis interviews.

To better observe interaction during testing and to be able to capture the problems that may occur in help usage, it is interesting that the help designer be present during observations, so that she may focus specifically on help issues. She may not only observe problems in accessing help expressions and in understanding their responses, but also find out user difficulties that hadn't been anticipated (and therefore had no associated help), or whose responses did not address the user's current problem. In our case study, this step made it possible to determine problems in the help content and in accessing help. These problems were grouped into three classes: help content, "declining" help, and help culture.

Help Content. During testing, the help designer observed users having problems in situations unanticipated by her, which meant that the corresponding help was inadequate or altogether missing.

"Declining" Help. When a user, after many fruitless attempts to use the searching mechanism, made a local help request, she read the explanation, spontaneously said she understood it, but even so she decided to do something different from what was said in the help content, which made it impossible to carry out the task defined in the test scenario.

Help Culture. Most users didn't access help, independently of their experience with the application or in using computers. There isn't a culture of asking for online help when you are in trouble. Few were those who asked for help and, when they did, some of them closed the help window before there was time for them to have read the help information. Only one user actually read the help text and followed what the explanation suggested.

\section{Conclusion}

In this paper, we have shown why, in Semiotic Engineering, online help system is an essential part of an application. It is through help that the designer can directly communicate with the application users, revealing the reasons underlying her design and how users may make better use of it. In this approach, model-based design is of utmost importance, for it makes it possible to maintain the consistency between the design products built at each phase. This allows the designer to create and convey a cohesive message to users, in order to increase their chances of making sense of her message.

The users may also express their doubts more directly using one of the available local help expressions during interaction. The response will be a fragment of the de- signer's point of view and rationale when designing the application. Moreover, users may delve deeper into the help content from the recurrence points available at each help response, in an indefinitely long chain of associations driven by their local needs. This process is associated to some fundamental concepts in semiotic theory, namely semiosis and abduction.

In addition to all technical and theoretical efforts, we should also pay attention to introducing changes in the way users perceive help. As a rule, users access help only as a last resort [5]. They may have had frustrating experiences in the past, or not even understand what help is for. We have argued that this perception is motivated by the attempt to design fail-proof interfaces, instead of conveying to users strategic information to encourage creative and intelligent use of computer artifacts. By adopting a Semiotic Engineering perspective for designing user interfaces and help systems, and thus opening a direct communication channel from designers to users, we believe our approach is a first step towards the introduction of a new culture for using help systems and computer artifacts.

By following a model-based approach, the cost of extending current design practices to design help according to our view is reduced. In order to further increase the benefits of our work, our students at PUCRS and PUCRio are working on software tools for aiding the design of online help.

\section{Acknowledgements}

The authors would like to thank PUCRS, PUC-Rio, and $\mathrm{CNPq}$ for supporting their research. They also thank the Semiotic Engineering Research Group at PUC-Rio for invaluable discussions that have contributed to this work.

\section{References}

[1] P. Adler, T. Winograd. Usability: Turning technologies into tools. Oxford University Press, 1992.

[2] S.D.J. Barbosa, C.S. de Souza, M.G. de Paula, M.S. Silveira. Modelo de Interação como Ponte entre o Modelo de Tarefas e a Especificação da Interface. In Simpósio Brasileiro de Fatores Humanos em Sistemas Computacionais, Fortaleza, 2002. pp.27-39.

[3] R.M. Baecker et al. Readings in Human- 
Computer Interaction: toward the year 2000. Morgan Kaufmann Publishers, Inc, San Francisco, 1995.

[4] J.M. Carroll (ed.) Minimalism Beyond the Nurnberg Funnel. The MIT Press, Cambridge, 1998.

[5] J.M. Carroll, M.B. Rosson. Paradox of the Active User. In: J. Carroll Interfacing Though: Cognitive Aspects of Human-Computer Interaction. Cambridge, MA: The MIT Press, 1987. pp.80-111.

[6] I. Ceaparu, J. Lazar, K. Bessiere, J. Robinson, B. Shneiderman. Determining Causes and Severity of End-User Frustration. Technical Report, HCIL-2002-11, CS-TR-4371, UMIACS-TR2002-51, 2002.

[ftp://ftp.cs.umd.edu/pub/hcil/Reports-AbstractsBibliography/2002-11html/2002-11.pdf, visited in March, 2004]

[7] L. Chamberland. Componentization of HTMLBased Online Help. In Proceedings of the Seventeenth Annual International Conference on Computer Documentation, ACM Press, pp.165168. 1999.

[8] J. Chu-Carrol, S. Carberry. Collaborative Response Generation in Planning Dialogues. Computational Linguistics, 3, 1998. pp.355-400.

[9] C.S. de Souza. The Semiotic Engineering of Human-Computer Interaction. The MIT Press, Cambridge, 2005.

[10] C.S. de Souza, R. Prates, T. Carey, T. Missing and Declining Affordances: are these appropriate concepts?. Journal of the Brazilian Computer Society, Number 1, Volume 7, July 2000. pp.2633.

[11] D.K. Farkas. Layering as a Safety Net for Minimalist Documentation. In J.M. Carroll (ed.) Minimalism Beyond the Nurnberg Funnel. The MIT Press, Cambridge, 1998. pp.247-274.

[12] B. Hansen, D. G. Novick, S. Sutton.Systematic Design of Spoken Prompts. In Proceedings of CHI'96, ACM Press, 1996. pp.157-164.

[13] W. L. Johnson, A. Erdem,. An Interactive Explanation of Software Systems. Automated Software Engineering, 4, 1997. pp.53-75.

[14] G. Kearsley. Online Help Systems: design and implementation. Norwood: Ablex Publishing Corporation. 1988.

[15] S. Kedar, C. Baudin, L. Birnbaum, R. Osgood,
R. Bareiss. Ask How it Works: An Interactive Intelligent Manual for Devices. In Proceedings of the INTERACT'93 and CHI'93, ACM Press, 1993. pp.171-172.

[16] M. Marx, C. Schmandt. MailCall: Message Presentation and a Navigation in a Nonvisual Environment. In Proceedings of $\mathrm{CHI}^{\prime} 96$, ACM Press, 1996. pp.165-172.

[17] V. O. Mittal, J. D. Moore. Dynamic Generation of Follow on Question Menus: Facilitating Interactive Natural Language Dialogues. In Proceedings of CHI'95, ACM Press, 1995. pp.90-97.

[18] Nielsen, J. Usability Engineering. Cambridge, MA: Academic Press. 1993.

[19] ORÉ, Projeto. In: http://serg.inf.puc-rio.br/ore, 2002.

[20] F. Paternò. Model-Based Design of Interactive Applications. Springer-Verlag, Londres, 1998.

[21] R.O. Prates, C.S. de Souza, S.D.J. Barbosa. A Method for Evaluating the Communicability of User Interfaces. ACM Interactions, Jan-Feb 2000. pp.31-38.

[22] J. Preece, Y. Rogers, E. Sharp, D. Benyon, S. Holland, T.Carey. Human-Computer Interaction. Addison-Wesley, Reading, 1994.

[23] M. Priestley. Task Oriented or Task Disoriented: Designing a Usable Help Web. In Proceedings of SIGDOC 98, ACM Press, 1998. pp.194-199.

[24] A. Puerta. The Mecano Project: Comprehensive and Integrated Support for Model-Based Interface Development. In J. Vanderdonckt (ed) Computer-Aided Design of User Interfaces. Presses Universitaires de Namur, Namur, 1996. pp.19-25.

[25] A. Puerta. A Model-Based Interface Development Environment. IEEE Software, 14(4), July/August, 1997. pp.41-47.

[26] H. Purchase, J. Worrill. An empirical study of on-line help design: features and principals. International Journal of Human-Computer Studies 56, 2002. pp.539-567.

[27] B. Raskutti, I. Zukerman. Generating Queries and Replies during Information-Seeking Interactions. International Journal of Human-Computer Studies, 47, 1997. pp.689-734.

[28] L. Rintjema, K. Warburton. Creating an HTML Help System for Web-based Products. In Proceedings of the Sixteenth Annual International 
Conference on Computer Documentation, ACM Press, 1998. pp.23-28.

[29] A. W. Roesler, S. G. McLellan. What Help Do Users Need? Taxonomies for On-line Information Needs \& Access Methods. In Proceedings of CHI'95, ACM Press, 1995. pp.437-441.

[30] A. Sellen, A. Nicol. Building User-Centered Online Help. In B. Laurel. The Art of HumanComputer Interface Design. Addison-Wesley, Reading, 1990. pp.143-153.

[31] B. Shneiderman. Designing the User Interface: Strategies for Effective Human-Computer Interaction, $3^{\text {rd }}$ edition. Reading, MA: AddisonWesley, 1998.

[32] M.S. Silveira, S.D.J. Barbosa, C.S. de Souza. Augmenting the Affordance of Online Help
Content. In Proceedings of IHM-HCI 2001, Springer-Verlag, Lille, 2001. pp.279-296.

[33] M. E. Sleeter. OpenDoc - Building Online Help for a Component-Oriented Architecture. In Proceedings of SIGDOC 96, 1996. pp.87-94.

[34] G. C. van der Veer, M. van Welie. Groupware Task Analysis. Tutorial Notes for the CHI99 workshop "Task Analysis Meets Prototyping: Towards seamless UI Development", May 1999, Pittsburgh PA, USA. Retrieved February 26, 2004, from http://www.cs.vu.nl/ martijn/gta/. 